\title{
A Rating System for Sustainability of Industrial Projects with Application in Oil Sands and Heavy Oil Projects: Areas of Excellence, Sub-Divisions, and Management Interactions
}

\author{
Cesar A. Poveda \\ Department of Mechanical Engineering, University of Alberta \\ 4 - 9 Mechanical Engineering Building, University of Alberta, Edmonton, Alberta T6G 2G8, Canada \\ Tel: 1-780-619-1872Ｅ-mail: poveda@ualberta.ca \\ Michael G. Lipsett (Corresponding Author) \\ Department of Mechanical Engineering, University of Alberta \\ 5 - 8J Mechanical Engineering Building, University of Alberta, Edmonton, Alberta T6G 2G8, Canada \\ Tel: 1-780-492-9494 E-mail: mlipsett@ualberta.ca
}

Received: May 25, 2011

Accepted: June 16, 2011

doi:10.5539/jsd.v4n4p3

\begin{abstract}
In the structure of the WA-PA-SU project sustainability rating system, three main aspects are considered: areas or categories of excellence, each with a set of criteria; areas or subdivisions of an oil sands or heavy oil project; and management integration. The resources involved in project development, expectations of stakeholders, and potential environmental impact define the ten areas or categories of excellence: project \& environmental management excellence (PEME); site \& soil resource excellence (SSRE); water resource excellence (WRE); atmosphere \& air resource excellence (AARE); natural \& artificial lighting excellence (NALE); energy resource excellence (ERE); resources \& materials excellence (RME); innovation in design \& operations excellence (IDOE); infrastructure \& buildings excellence (IBE); and education, research \& community excellence (ERCE). The structure of the rating tool considers the complexity and size of oil sands and heavy oil projects, dividing them in nine different areas or sub-divisions: project integration, provisional housing/buildings, permanent housing/buildings, roads, oil transportation \& storage, mining process, in-situ process, upgrading \& refining, and shutdown \& reclamation. The development of the WA-PA-SU project sustainability rating system offers a proactive approach, which aligns with sustainability principles, for oil sands and heavy oil projects throughout their life cycle phases, the project management processes (e.g. initiation, planning, execution, monitoring and control, and close-out), and the life cycle of sub-projects and processes.
\end{abstract}

Keywords: Sustainable development, Environmental issues, Ratings, Energy efficiency, Energy consumption

\section{Introduction}

Rating systems have been very successful in influencing design and operation of buildings in more sustainable ways. This approach can be applied to other types of built environment, such as the development, operation, and close-out of heavy industrial facilities. The construction industry, including architecture and engineering practices, has been revolutionized by the implementation of sustainable rating systems, compelling practitioners to examine the effects of project work from a broader perspective than merely meeting a narrow set of technical specifications and a budget (Yudelson 2008). The transformation of the building market reflects a growing public awareness of environmental matters, beyond what is regulated as a matter of public policy. Stakeholder expectations have also evolved in oil sands and heavy oil development. There is growing recognition by owners and operators oil sands and heavy oil projects that the environmental and social impacts of these projects require just as much planning and stewardship as economic performance and compliance with regulations. While the buildings industry can use a wide variety of environmental assessment tools or sustainable rating systems, the oil and gas industry lacks the necessary tools to assess the overall sustainable development performance of the projects.

The building industry worldwide has developed a number of rating systems. BREEAM (Building Research Establishment Environmental Assessment Method) was established in 1990 in the UK (BREEAM 2009). This was followed by several others, including the LEED 1 pilot in 1998 (USGBC 2007). Environmental assessment tools have been designed to meet the requirements of the construction industry (e.g. buildings); and they can be used to assess building components, whole building frameworks, and whole buildings. Different types of buildings can be assessed: existing buildings, new buildings, refurbishment of a building, and building product/component. According to building use, assessment tools can be classified for residential buildings, office buildings, and other applications, such as healthcare and education. Specialized sustainable rating systems have 
been designed as the industry recognizes the applicability and benefits, for example LEED for Neighbourhood Developments.

Among the users of the sustainable rating systems are engineers, architects, constructors, consultants, building products fabricators, owners and/or investors, government and non-government authorities, and researchers. Haapio and Viitaniemi 2008, included in their study six phases of a building life cycle: production of material and components, construction, use/operation of building, maintenance, demolition, and disposal (recycling, landfill, incineration for energy recovery, etc). Most rating systems users employ the sustainable rating system throughout the project life cycle, but some focus on specific areas, for example, building product fabricators, who contribute to only part of the entire cycle.

Designing a new sustainable rating system in a new application area involves considerations of how to implement a practical system, which goes beyond enumerating a set of technical issues to how decisions are made. In a large industrial application, decision influencers come from different stakeholder groups, not just the client and neighbours who may be affected by the introduction of a new building. Since the WA-PA-SU project sustainability rating system is the first of its kind it faces several challenges, mainly because the primary focus of the tool is projects in oil sands and heavy oil. Buildings are a sub-division of such projects; and existing sustainable rating systems focus on environmental performance of buildings. In large industrial projects, the major expected environmental impacts occur in areas of the projects beyond buildings; and a sustainable rating system has not yet been developed for these other areas.

Because of the type of buildings, the different users, and the project life cycle phases supported by the sustainable rating systems, different interested parties have become involved since rating tools have been applied. Government organizations, non-governmental agencies, and research groups have contributed through experience and development of new technology. Moreover, Technical Committee (TC) 59 and Subcommittee (SC) 17 of the International Organization for Standardization (ISO) is currently working in defining standardized requirements for the environmental assessment of buildings (ISO 2006a, ISO 2006b, ISO 2007, ISO 2008, ISO 2010); the Technical Committee (TC) 350 of European Committee for Standardization (CEN) is developing a voluntary standardized methods for the assessment of the sustainability aspects of new and existing construction works and for standards for the environmental product declaration of construction product (CEN 2009, CEN 2009a, CEN 2009b, CEN 2009c); and Committee B/558 of British Standard Institution (BSI) is developing a set of standards on sustainability of building construction (BSI 2007a, BIS 2007b, BIS 2010).

Rating systems can be categorized. Trusty (2000) describes the "Assessment Tool Typology" introduced by ATHENA institute which has three levels: Level 1, product comparison tool and information sources; Level 2, whole building decision support tools; and Level 3, whole building assessment framework or systems. The International Energy Agency (IEA) Annex 31 grouped the tools in two main categories: interactive software and passive tools. IEA Annex 31 explains that environmental assessment tool should truly measure factors having environmental impact, easily adapt to specific buildings and locations, quickly rank results, and be transparent in their assumptions (IEA Annex 31 2005).

Challenges experienced during development and implementation of other sustainable rating systems are being taken into consideration to design a tool that meets the needs of the oil sands and heavy oil project owners, operators, and stakeholders. Although most sustainable rating systems support the users in each of the described phases of the project life cycle, the WA-PA-SU project sustainability rating system also includes the phases of project planning and design, by defining criteria to meet environmental regulations and standards. These two phases are critical for the success of the projects, because specifications defined during project development link to the points that are allocated to each criteria in the rating system. In this way, the project plan can ensure that the project can satisfy the criteria in the rating tool.

Stakeholder expectations, industry type, and project size are some of the criteria considered to develop the WA-PA-SU project sustainability rating system structure. This structure consists of phases of the project life cycle, areas or sub-divisions of the project, and areas of excellence related to economic, environmental, and social performance. As described above, the tool is applied over time, from the planning stage through to project decommissioning and closure. The complexity and scale of a project makes it necessary to subdivide the project in two ways: according to processes (e.g. mining process, in-situ process) and engineering areas (e.g. permanent housing/buildings, roads). This differentiation leads to nine areas or subdivisions within a project. Ten areas of excellence are also defined, according to the natural resources that are affected by a project. These areas of excellence will be discussed in the following section.

\section{Areas or Categories of Excellence}

Each sustainable rating system uses different areas of environmental impact, categories of interest, and strategies for analysis and decision-making processes. The structure varies according to the developer of the particular tool. In the construction industry, two of the most recognized environmental assessment methodologies - that is, sustainable rating systems - are BREEAM (Building Research Establishment Environmental Assessment Method) and LEED (Leadership in Energy and Environmental Design) (Inbuilt 2010). BREEAM operates in dozens of 
countries and more than 200,000 buildings have obtained the required score to be certified under one of the five categories: pass, good, very good, excellent or outstanding (Dutch Green Building Council 2010). BREEAM uses eight categories to address environmental issues: management, health \& well-being, energy, transport, water, materials \& waste, land use \& ecology, and pollution. LEED has presence in over 90 countries with 2,476 certified projects and 19,524 registered projects (USGBC 2009). LEED addresses five key areas/categories: sustainable sites (SS), water efficiency (WE), energy \& atmosphere (EA), materials \& resources (MR), and indoor environmental quality (IEQ). Innovation in Design (ID) and Innovation in Operations were added in the latest version of LEED. Additional areas or categories are used in specific LEEd rating systems. Examples include location \& linkages (LL) and awareness \& education (AE) in LEED for homes, and smart location \& linkage (SLL), neighborhood pattern \& design (NPD), and green infrastructure \& building (GIB) in LEED for neighborhood development (U.S. Green Building Council 2011a, U.S. Green Building Council 2011b).

The WA-PA-SU project sustainability rating system takes into consideration the resources involved in project development, stakeholder expectations, and potential environmental, economic, and social impact; these three general facets of the project comprise ten areas of excellence: project \& environmental management excellence (PEME); site \& soil resource excellence (SSRE); water resource excellence (WRE); atmosphere \& air resource excellence (AARE); natural \& artificial lighting excellence (NALE); energy resource excellence (ERE); resources \& materials excellence (RME); innovation in design \& operations excellence (IDOE); infrastructure $\&$ buildings excellence (IBE); and education, research \& community excellence (ERCE). Each of these areas is described below.

\section{[a] Project \& Environmental Management Excellence - PEME}

Effective management is critical to project performance and sustainability, because management practices have an impact throughout the project life cycle, in activities such as planning, commissioning, construction, operations, etc. The Project \& Environmental Excellence Area considers management focus areas, including (but not limited to) commissioning practices, targets for operational improvement, environmental management systems, environmental risk management, employee retention, documentation \& manuals, and policies, plans, and programs (PPP) implemented at the top level of management.

\section{[b] Site \& Soil Resource Excellence - SSRE}

Project site and soil resources have impacts on the three areas of the foundation of sustainability: economy (e.g. costs related to man-made infrastructure), environment (e.g. destruction and restoration of wildlife habitat), and society (e.g. protection of diverse animal and plant species as people seek connections with their natural surroundings and with each other). A number of related aspects are considered: effective use of areas (e.g. brownfield site), transportation, site design, ecological enhancements, stewardship of existing ecological features, handling of storm water, pollution mitigation, erosion prevention, etc. The interaction between project and site, and the impact that the project has on the ecosystems and other resources, are part of developing a more sustainable site. The key goals of the Site \& Soil Resource Excellence Area are to promote responsible site development \& soil management, and to minimize environmental, social and economic impacts on different ecosystems.

\section{[c] Water Resource Excellence - WRE}

As development expands in a region, the consumption of water increases and the available water supply may decrease. Oil sands and heavy oil projects require industrial and potable water to operate. While a significant amount of water is needed for industrial processes, potable water is also required to meet the needs of buildings systems and the occupants. The operation of oil sands and heavy oil projects impacts rivers, lakes, and other water sources in the neighborhoods of the area of operation. Produced water from deep geological features may be saline and inorganic compounds. Production may lead to contamination of some water inventories with process chemicals (such as surfactants), metals \& metal salts, organic compounds, other chemicals, and waste from the plant. The Water Resource Excellence Area objectives range from optimizing water consumption to preventing water contamination in the open environment.

\section{[d] Atmosphere \& Air Resource Excellence - AARE}

The operation of oil sands and heavy oil projects entails a certain level of air pollutants: carbon monoxide, carbon dioxide, nitrogen oxides, ozone, sulphur oxides, and particulate matter. High levels of air contaminants have direct effects on the environment (e.g. acid rain and vegetative stress) and humans (e.g. respiratory health issues). While the quality of the air is monitored where industrial processes occur (e.g. mining processes and surroundings), other areas of the projects to be considered include indoor air quality (e.g. buildings). Atmosphere \& Air Resource Excellence aims to monitor, control and minimize air quality pollutants.

\section{[e] Natural \& Artificial Lighting Excellence - NALE}

While $20 \%$ to $50 \%$ of total the energy consumed by an average building (e.g. home and offices) is due to lighting (Hawken et al. 2000), buildings are a relatively small component of oil sands and heavy oil projects capital, material usage, and energy-related expenditure. Different components of the projects use considerably 
different amounts of artificial lighting (indoor and outdoor). For instance, mining operations require spot lighting in some parts of the operation, and refinery facilities are lit so that operators and maintainers can do check equipment checks and perform maintenance safely. The availability of natural light changes with the time of year. The principles of Natural \& Artificial Lighting Excellence are to reduce the use of artificial lighting, maximize natural lighting across the projects, and monitor and control lighting quality.

\section{[f] Energy Resource Excellence - ERE}

Greenhouse gas emissions are directly linked to energy consumption, especially in facilities that are powered by fossil fuels. Carbon dioxide, methane, ozone, water vapour, and nitrous oxides are the most abundant greenhouse gases in the atmosphere. Large industrial operations and buildings are among the larger consumers of energy. For policymakers, energy is an economic and environmental issue that impacts the development of projects, from the earliest stages of planning and commissioning. To meet its objectives, Energy Resource Excellence addresses energy management, energy demand, energy efficiency consumption, energy performance, and renewable energy throughout the project life cycle.

\section{[g] Resources \& Materials Excellence - RME}

This area of excellence considers not only the raw materials used and but also the embodied energy used to develop the elements in the different facilities that comprise an oil sands or heavy oil project. Due to the different equipment and systems of these projects, the range and amount of materials used has a direct impact on the environment, economy, and society. Resources \& Materials Excellence (RME) focuses on the waste management strategy of reducing, reusing, and recycling to minimize waste. Among the range of materials that can be employed, RME considers materials with low embodied energy, regional materials, use of sustainable resources, renewable materials, and life cycle impacts.

\section{[h] Innovation in Design \& Operations Excellence - IDOE}

The success of an industry relies on the ability to improve its processes and procedures through technological innovation and changes in business practices. Implementing these changes brings economic and environmental benefits, along with an impact on society. Innovation in Design \& Operations (IDOE) motivates practitioners to find efficient and effective alternatives for delivering their projects. Aligning proactive approaches to sustainability with industry goals is the main objective of IDOE.

\section{[i] Infrastructure \& Buildings Excellence - IBE}

Complex projects are composed of a variety of equipment with associated infrastructure, such as buildings, bridges, roads, piping, and utilities. Oil sands and heavy oil projects are no exception. All elements of each structure in the project must work in harmony and as an integrated whole to deliver project requirements, as well as to achieve sustainable goals and excellence in environmental performance. Most infrastructure impacts specific resources (e.g. soil or water) while affecting the structure as a whole. The intent of the Infrastructure \& Buildings Excellence Area is to monitor elements that affecting the functionality of the project infrastructure are to minimize any negative environmental and social effects.

\section{[j] Education, Research \& Community Excellence - ERCE}

The engagement of different stakeholders is crucial for successful sustainable development of oil sands and heavy oil projects. Companies have been putting increasing effort into effective engagement with regional stakeholders. Education, Research \& Community Excellence (ERCE) mainly addresses the societal element of a project, and linking impacts to the other two pillars of sustainability: economy and environment. ERCE focuses on the involvement of the community, including education, training, and research programs.

\section{Sub-Divisions}

Evaluation of a project generally requires assessment of elements within the project. As discussed above, existing rating systems are designed primarily for environmental assessment of an entire building, or for product comparison.

Each rating system supports different types of buildings. LEED and BREEAM developed different versions for a variety of building types. LEED Accredited Professional program is integrated by a number of specialties, divided in five main categories: [1] Green Building Design \& Construction (LEED for New Construction and Major Renovations, LEED for Core \& Shell Development, LEED for School, LEED for Healthcare, and LEED for Retail New Construction); [2] Green Interior Design \& Construction (LEED for Commercial Interior and LEED for Retail Interiors); [3] Green Building Operation \& Maintenance (LEED for existing Buildings: Operations \& Maintenance); [4] Green Neighborhood Development (LEED for Neighborhood Development); and [5] Green Home Design \& Construction (LEED for Homes) (U.S. Green Building Council 2011a, U.S. Green Building Council 2011b).

BREEAM offers a wide range of tools to assess the environmental performance of any type of new or existing building. For common buildings, BREEAM developed standard versions. Other types of buildings are assessed against tailored criteria using the Bespoke BREEAM version. BREEAM has different versions for courts, retail 
stores, offices, schools, prisons, healthcare facilities, industrial plants, multi-residential buildings, and other specialized buildings (Dutch Green Building Council 2010, BREEAM 2010).

Other rating systems also specialize in environmental assessment of buildings. Although buildings are a component of the oil sands and heavy oil projects, they do not provide the main economic, social, and environmental impacts. The WA-PA-SU project sustainability rating system methodology divides a complex industrial project into nine different sub-divisions: project integration, provisional housing/buildings, permanent housing/buildings, roads, oil transportation \& storage, mining process, in-situ process, upgrading \& refining, and shutdown \& reclamation. A direct relationship exists between the areas or categories of excellence and these sub-divisions, as illustrated in Table 1. The assessment criteria follow under each area or category of excellence, depending on the relevant sub-division. When evaluating the sustainability contribution of a particular aspect of a project, credit cannot be claimed more than once, if the value has been already accrued by implementing the requirements within one or more of the other subdivisions.

[a] Project Integration considers plans, programs, polices, regulations, processes, procedures, and other information that concerns the project as a whole. Other sub-division criteria are subsidiaries of the project integration sub-division criteria. In case of confusion as to whether the value of a part of a project belongs in one sub-division or another, the project integration criteria prevail to resolve the ambiguity for issues that could be assigned to more than one sub-division. These integration criteria become the basis for clarification in case of synergies and/or trade-offs.

[b] Provisional Housing/Buildings include mobile homes, temporary buildings or any other structure for a purpose of human living or offices. Mobile homes are usually built off-site, and so green standards during installation, operation, and demobilization must be met by the supplier. Temporary buildings and other structures are built with similar standards as permanent housing/buildings; but their useful life is typically shorter. The provisional housing/building sub-division may also include structures outside the project limits. This situation can arise for companies that are developing projects for which the operating phases of the projects have not yet started (e.g., exploration). Also included are community programs that require construction of temporary living accommodations.

[c] Permanent Housing/Buildings are designed and built for durability. Long-term structures for human habitation, offices, and meeting places, parking and green areas, and walkways located close to permanent structures are included in this sub-division. As in the provisional housing/buildings, these structures may be located outside of the project limits, but must link to the project in some way.

[d] Roads are classified in three ways. Primary roads are main thoroughfares built and maintained by government agencies (e.g. highway \# 63, highway \# 881). Secondary roads connect the projects with primary roads. Tertiary roads are located within the project limits. Technical requirements vary for each type of road, and minimum standards will be mandated by regulation and operating licenses. The roads sub-division includes roads built and maintained by developing companies, which usually involves only secondary and tertiary roads. The WA-PA-SU project sustainability rating system includes in its assessment any roads in which the developing companies are involved in construction and/or maintenance.

[e] Fluid Transportation \& Storage consists of the multiple pipeline systems within the project. Pipelines are used to transport water from streams and rivers onto the project site, move produced water to storage ponds on the site, handle bitumen-rich slurries prior to separation, and to ship bitumen, condensate, and oil products to other locations. Pipelines are also used to transport produced solids for storage and eventual reclamation. Oil storage usually occurs in tanks, generally above ground close to the upstream production facility and where any upgrading process occurs. Stored oil is transported to end users or further storage facilities using pipelines or road tankers.

[f] Mining Process and related processes to recover bitumen by removal of overburden from a surface-mineable oil sands deposit are included in this sub-division. Current mining methods are based on shovels to fragment and load the ore onto trucks which transport the ore to a slurrying facility, where the oil sands are mixed with hot water and reagents to promote bitumen separation in a centralized extraction plant. Following bitumen separation, a hydrocarbon diluent is added to improve the bitumen quality by removing water and solids. The mining process sub-division includes any processes required to produce dry bitumen that can be transported to an upgrader, plus the handling of non-product materials stored in settling basins and engineered tailings structures. Sustainable development objectives in this sub-division include reduced energy intensity, reduced amount and duration of footprint (disturbance to terrestrial and aquatic environments before return to equivalent environmental capability), and reduced emissions.

[g] In-situ Process uses drilling to access and produce hydrocarbon, and does not leave behind large tailings ponds after recovering the bitumen. This process is used for heavy oil production, and for bitumen that is too deep for economical surface mining and is in a favourable geological formation, typically with cap rock to prevent loss of formation pressure, typically from deposits at depths of 350-600 meters below the surface. Current processes include cyclic steam stimulation (CSS), steam-assisted gravity drainage (SAGD), vapour 
recovery extraction (VAPEX), cold heavy oil production with sand (CHOPS), and others (Kelly 2009). This sub-division includes processes and equipment to the point at which heavy oil or diluted bitumen can be transported for upgrading. Key sustainable development objectives in this sub-division are reduced energy consumption and prevention of long-term contamination of aquifers.

[h] Upgrading \& Refining processes occur separately from upstream production of heavy oil and bitumen. The bitumen from the oil sands is viscous and has limited value. The upgrading process produces a higher value-added product by either removing carbon or adding hydrogen, to produce synthetic crude oil, which has higher economic value than bitumen. The upgrading process also removes contaminants, such as sulphur, nitrogen, heavy metals, and salt. Upgrading comprises three basic processes: [1] hydroprocessing to convert the residuals and asphaltenes by coking or hydro-conversion, possibly with solvent deasphalting; [2] distillation to separate products with different boiling points; and [3] hydrotreating to add hydrogen to improve product quality (Speight 2009). Other processes remove contaminants that would affect the quality of the synthetic crude oil (SCO), which is used as feedstock for producing transportation fuels (diesel, gasoline, and jet fuel).

[i] Reclamation \& Closure are the activities that occur after the resource has been extracted. Reclamation restores terrestrial and aquatic ecosystems to the state of equivalent environmental capability to the original ecosystems that were present before the industrial activity took place. The reclamation process differs depending on the process that took place (e.g. mining process, in-situ process), and may include restoration of pits at mine sites, removal of equipment and infrastructure, capping of tailing impoundments, construction of landforms, and long-term monitoring for geotechnical stability and viability of engineered ecosystems as they transition to naturally sustaining ecosystems.

\section{Management Interactions}

The success of the WA-PA-SU project sustainability rating system and achievement of its objectives depends on its interaction with different levels of management within the project and operating organization. As a decision-making support tool, the rating system must support a project throughout the project life cycle, including the project management processes, groups existing in internal projects (i.e. sub-projects), and process life cycles. Management is divided into three levels within the rating system: project, fundamental, and operational, as illustrated in figure 1. Criteria for gauging their effectiveness in delivering sustainable business performance will involve all three levels.

[a] Project Level: Project Life Cycle. Alberta Energy (2009) divides an oil sands project into four stages. Stage 1 is comprises the resource assessment and rights and exploration phases, to estimate the recoverable reserve for a potential project. Stage 2 involves project development, project approval, and construction. Stage 3 is operating the plant, which generates sales and royalties. Stage 4 closes the project through reclamation activities and closure. During the life cycle of the oil sands and heavy oil projects, a series of internal projects (that is, sub-projects) and processes occur. These sub-projects and process align with the plans, polices, and program of a project. The developing company may have a stake in more than one project as part of its strategy. Subsequently, different project management processes are applied; but not all of them take place in each sub-project or process, either in the same order or to the same rigour. Although every project has unique aspects, oil sands and heavy oil projects have similar phases and deliverables, albeit with varying duration of each phase, and quantity of deliverables.

[b] Fundamental Level: Project Management Processes Groups. Since each developing company manages projects in a specific way, the WA-PA-SU project sustainability rating system uses rating criteria based on standard management practices that are generic to any project. The Project Management Institute identifies five project management processes groups: initiation, planning, executing, monitoring \& control, and closing (PMBok 2008). A project phase is different from a project management process group (PMBok 2008). Each project (or sub-project process, or project phase) is aligned and connected to facilitate coordination and to increase the probability of overall project success. The activities occurring in a project management process group affect decisions and actions taken in other groups. In oil sands and heavy oil projects, some processes are iterated many times times while other processes have long durations. Differentiation is made as the processes are applied to the project level or operational level.

[c] Operational Level: Sub-Projects Life Cycle and Processes Life Cycle. Development of an oil sands project or heavy oil project consists of a series of endeavours categorized in sub-projects and processes. Sub-projects such as building construction can be thought of as projects on their own, which occur within the main project. Some processes in a project repeat themselves numerous times, especially during the operational stage. Sub-projects and processes use the project management groups to organize, direct, and execute the activities within their respective scope. The interaction between the operational level and fundamental and project level is critical to minimize negative impacts and to maximize the positive outcomes expected in the project. Communication channels are an effective support tool to reduce interferences amongst different sub-projects and processes. 
A direct relationship exists amongst the three management levels (e.g. project, fundamental, and operational) and the criteria that are used in a rating system. Each area of excellence contains a series of criteria which are classified according to the sub-project or process phase, and where and when that set of activities occurs within the overall project. Figure 2 shows an example of a sub-project life cycle - the life cycle of a building - and its associated criteria. Each area of excellence examines sub-projects and processes to determine the different criteria. Criteria use acronyms to differentiate between each other; for example, ERCEP\&D3xx refers to certain criteria (xx) that belong to sub-division three (3) for the education, research, and community excellence area (ERCE) during the planning \& design (P\&D) phase.

\section{Conclusions and Future Work}

The design of the WA-PA-SU project sustainability rating system considers the three components of sustainability: economy, society, and environment. As every project has a certain level of environmental impact, it is recognized that not every project has the same level of social and economic impact. Sustainability principles and different types of impacts define the WA-PA-SU project sustainability rating system as a transparent verification process to assist companies in demonstrating sustainable development performance during a project life cycle, through the implementation of enhanced strategies to mitigate environmental and social impacts while delivering economic benefits.

Air, water, and land are the three main resources related to operations and environmental impact of oil sands and heavy oil projects; however, there are also other resources to consider. The ten areas of categories of excellence in the WA-PA-SU project sustainability rating system revisit not only the resources that are potentially environmentally affected by the projects, but also social and economic areas that contribute to sustainable development. Resources and materials used during construction and operation of an industrial project are included, based on their impact throughout their life cycle. Research, education, community involvement, and innovation are among the areas that contribute to the success of a project, and yet they are not commonly measured or included in a sustainability rating system. People, planet, and profit are all considerations when assessing the viability of a project.

The different sub-divisions included in the WA-PA-SU project sustainability rating system align with different phases included in oil sands and heavy oil projects. Certainly, most of the sub-divisions refer to sub-projects in the construction, operation, and close-out stages; but the project integration sub-division includes criteria that refer to the initial project development. The main objective behind each sub-division is to support the sub-projects and processes of an overall large project throughout their life cycle, which means that each phase of an oil sands project or heavy oil project (or an expansion) must be supported by the tool as well. Each sub-division is intended to be independent and contains specific criteria according to the social, economic, and environmental goals; however, they are not in fact completely separate. For this reason, integration management ties up the other eight sub-divisions, so that projects work in harmony and synergistic aspects of a project can be captured and evaluated.

As different areas or categories of excellence and sub-divisions work together to avoid overlapping and negative synergies, management also acts in a coordinated fashion. The structure of the WA-PA-SU project sustainability rating system is meant to help management to apply appropriate criteria in different project contexts, whether it is a project management process, execution of a sub-project, operating a process, or delivering a project phase. This interaction assists different parties to meet the goals of the organization, while being able to steward to sustainable development targets.

This proposed framework can be used to develop specific criteria for each element within a sub-division and area of excellence, in each stage of a large industrial project. These criteria should be as objective as possible, and- to the degree possible - should not duplicate data collection that the company does for its own business purposes and for regulatory reporting. The decision process should be as open and transparent as possible, so that results are verifiable and less prone to interpretation. This transparency is important, because the implementation of the WA-PA-Su project sustainability rating system requires engagement of all parties that are involved in a large industrial project, from developing companies and contractors, through government officials and regulators, to community \& regional stakeholders. The approach used in the design and development facilitates data collection and interpretation of each criterion, without leaving out any important facet of the project impact (whether positive or negative). Work remains to be done to develop a rational method to compile an overall score for a project's sustainability. But the success of a rating system depends on the trust that the different parties have in the assessment tool, as much as in the approach for generating the assessment.

\section{References}

BSI (2007a). "BSI BS 21930. Sustainability in building construction - environmental declaration of building products," London, UK

BSI (2007b). "BSI BS 15392. Sustainability in building construction - general principals," London, UK

BSI (2010). "BSI BS 21931-1. Sustainability in building construction - framework for methods of assessment of the environmental performance of construction works," London, UK 
BREEAM. (2009). "About BREEAM buildings." < http://www.breeam.org/page.jsp?id=13> (Jan. 15, 2010).

BREEAM. (2010). "What is BREEAM." <http://www.breeam.org/page.jsp?id=66> (May 19, 2011).

CEN (2009). "CEN PREN 15643-2. Sustainability of construction works - assessment of buildings - Part 2: Framework for the assessment of environmental performance," Brussels, BE

CEN (2010a). "CEN PREN 15643-1. Sustainability of construction works - assessment of buildings - Part 1: General framework," Brussels, BE

CEN (2010b). "CEN PREN 15643-3. Sustainability of construction works - assessment of buildings - Part 3: Framework for the assessment of social performance," Brussels, BE

CEN (2009c). "CEN PREN 15643-4. Sustainability of construction works - assessment of buildings - Part 2: Framework for the assessment of economic performance," Brussels, BE

Dutch Green Building Council. (2010) "Dutch Green Building Council English." $<$ http://www.dgbc.nl/wat_is_dgbc/dgbc_english> (Jan 17, 2011).

Energy Alberta (2009). "Oil sands." < http://www.energy.alberta.ca/OurBusiness/oilsands.asp> (Jan 18 2010).

Haapio, A., Viitaniemi, P. (2008). "A critical review of buiding environmental assessment tools." Enviromental Impact Assessment Review, 28, 469-482.

Hawken, P., Lovins, A. \& Hunter, L. (2000). Natural Capitalism. Back Bay Press, Time Warner Book Group, New York, N.Y.

IEA Annex 31. (2005). "Energy related environmental impact of buildings - final revisions 2005." < http://www.iisbe.org/annex31/index.html> (Jan 18 2010)

Inbuilt (2010). “BREEAM versus LEED,” Inbuilt Ltd., Kings Langley, UK.

ISO. (2006a). "ISO/TS 21929-1. Sustainability in building construction - sustainability indicators - Part 1: framework for development of indicators for buildings," Geneva, SWZ.

ISO. (2006b). "ISO/DIS 21929-1. Sustainability in building construction - sustainability indicators - Part 1: framework for development of indicators for buildings," Geneva, SWZ.

ISO. (2007). "ISO 21930. Sustainability in building construction - environmental declaration of buildings products" Geneva, SWZ.

ISO. (2008). "ISO 15392. Sustainability in building construction - general principals" Geneva, SWZ.

ISO. (2010). "ISO/TS 21931-1. Sustainability in building construction - framework for methods of assessment for environmental performance of construction works - Part1: Buildings," Geneva, SWZ.

Kelly, G. (2009). The Oil Sands - Canada's Path to Clean Energy?. Cochrane, AB.: Kingsley Publishing Service Inc.

Project Management Institute (PMI ). (2008). A Guide to the Project Management Body of Knowledge (PMBOK ${ }^{\circledR}$ Guide 2008 Edition), PMI Publications, Pennsylvania, USA.

Speight, J.G. (2009). Ehhanced Recovery Methods for Heavy Oil and Tar Sands. Gulf Publishing Company. Houston, TX.

Trusty, W.B. (2000). "Introducing assessment tool classification system. Advance Building Newsletter \# 25, p. 18." < http://www.athenasmi.org/publications/publications.html $>$ (Jan 18, 2010).

U.S. Green Building Council. (2007). "LEED for Homes Program Pilot Rating System," Version 1.11a, Washington, D.C.

U.S. Green Building Council. (2009). "Green Building by the Numbers,” Washington, DC

U. S. Green Building Council. (2011a). Intro - What LEED is. Retrieve from http://www.usgbc.org/DisplayPage.aspx?CMSPageID $=1988$

U. S. Green Building Council. (2011b). Intro - What LEED measures. Retrieve from http://www.usgbc.org/DisplayPage.aspx?CMSPageID=1989

Yudelson, J. (2008). The Green Building Revolution. Island Press, Washington, D.C. 
Table 1. Relationship between sub-divisions and areas or categories of excellence

1. Project Integration

\begin{tabular}{cl}
\hline 1.1 & Project \& Environmental Management Excellence - PEME \\
\hline 1.2 & Site \& Soil Resource Excellence - SSRE \\
\hline 1.3 & Water Resource Excellence - WRE \\
\hline 1.4 & Atmosphere \& Air Resource Excellence - AARE \\
\hline 1.5 & Natural \& Artificial Lighting Excellence - NALE \\
\hline 1.6 & Energy Resource Excellence - ERE \\
\hline 1.7 & Resources \& Materials Excellence - RME \\
\hline 1.8 & Innovation in Design \& Operations Excellence - IDOE \\
\hline 1.9 & Infrastructure \& Buildings Excellence - IBE \\
\hline 1.10 & Education, Research \& Community Excellence - ERCE \\
\hline
\end{tabular}

4. Roads

4.1 Project \& Environmental Management Excellence-PEME

4.2 Site \& Soil Resource Excellence - SSRE

4.3 Water Resource Excellence - WRE

4.4 Atmosphere \& Air Resource Excellence - AARE

4.5 Natural \& Artificial Lighting Excellence - NALE

4.6 Energy Resource Excellence - ERE

4.7 Resources \& Materials Excellence - RME

4.8 Innovation in Design \& Operations Excellence - IDOE

4.9 Infrastructure \& Buildings Excellence - IBE

4.10 Education, Research \& Community Excellence - ERCE

7. In-situ Process

7.1 Project \& Environmental Management Excellence - PEME

7.2 Site \& Soil Resource Excellence - SSRE

7.3 Water Resource Excellence - WRE

7.4 Atmosphere \& Air Resource Excellence - AARE

7.5 Natural \& Artificial Lighting Excellence - NALE

7.6 Energy Resource Excellence - ERE

7.7 Resources \& Materials Excellence - RME

7.8 Innovation in Design \& Operations Excellence - IDOE

7.9 Infrastructure \& Buildings Excellence - IBE

7.10 Education, Research \& Community Excellence - ERCE
2. Provisional Housing/Buildings

3. Permanent Housing/Buildings

2.1 Project \& Environmental Management Excellence-PEME 2.2 Site \& Soil Resource Excellence - SSRE

2.3 Water Resource Excellence - WRE

2.4 Atmosphere \& Air Resource Excellence - AARE

2.5 Natural \& Artificial Lighting Excellence - NALE

2.6 Energy Resource Excellence - ERE

2.7 Resources \& Materials Excellence - RME

2.8 Innovation in Design \& Operations Excellence - IDOE

2.9 Infrastructure \& Buildings Excellence - IBE

2.10 Education, Research \& Community Excellence - ERCE

5. Fluid Transportation \& Storage

6. Mining Process

5.1 Project \& Environmental Management Excellence - PEME 5.2 Site \& Soil Resource Excellence - SSRE 5.3 Water Resource Excellence - WRE

5.4 Atmosphere \& Air Resource Excellence - AARE

5.5 Natural \& Artificial Lighting Excellence - NALE

5.6 Energy Resource Excellence - ERE

5.7 Resources \& Materials Excellence - RME

5.8 Innovation in Design \& Operations Excellence - IDOE

5.9 Infrastructure \& Buildings Excellence - IBE

5.10 Education, Research \& Community Excellence - ERCE

8. Upgrading \& Refining

9. Reclamation \& Closure

6.2 Site \& Soil Resource Excellence - SSRF

6.3 Water Resource Excellence - WRE

6.4 Atmosphere \& Air Resource Excellence - AARE

6.5 Natural \& Artificial Lighting Excellence - NALE

6.6 Energy Resource Excellence - ERE

6.7 Resources \& Materials Excellence - RME

6.8 Innovation in Design \& Operations Excellence - IDOE

6.9 Infrastructure \& Buildings Excellence - IBE

6.10 Education, Research \& Community Excellence-ERCE

8.1 Project \& Environmental Management Excellence - PEME 9.1 Project \& Environmental Management Excellence-PEME

\begin{tabular}{l|l|l}
8.2 & Site \& Soil Resource Excellence - SSRE & 9.2 Site \& Soil Resource Excellence - SSRE
\end{tabular}

$\begin{array}{ll}8.3 \text { Water Resource Excellence - WRE } & 9.3 \text { Water Resource Excellence - WRE }\end{array}$

8.4 Atmosphere \& Air Resource Excellence - AARE $\quad 9.4$ Atmosphere \& Air Resource Excellence - AARE

8.5 Natural \& Artificial Lighting Excellence - NALE $\quad 9.5$ Natural \& Artificial Lighting Excellence -NALE

8.6 Energy Resource Excellence - ERE

8.7 Resources \& Materials Excellence - RME

9.6 Energy Resource Excellence - ERE

8.8 Innovation in Design \& Operations Excellence - IDOE

9.8 Innovation in Design \& Operations Excellence - IDOF

8.9 Infrastructure \& Buildings Excellence - IBE

9.9 Infrastructure \& Buildings Excellence - IBE

8.10 Education, Research \& Community Excellence - ERCE

9.10 Education, Research \& Community Excellence - ERCE 


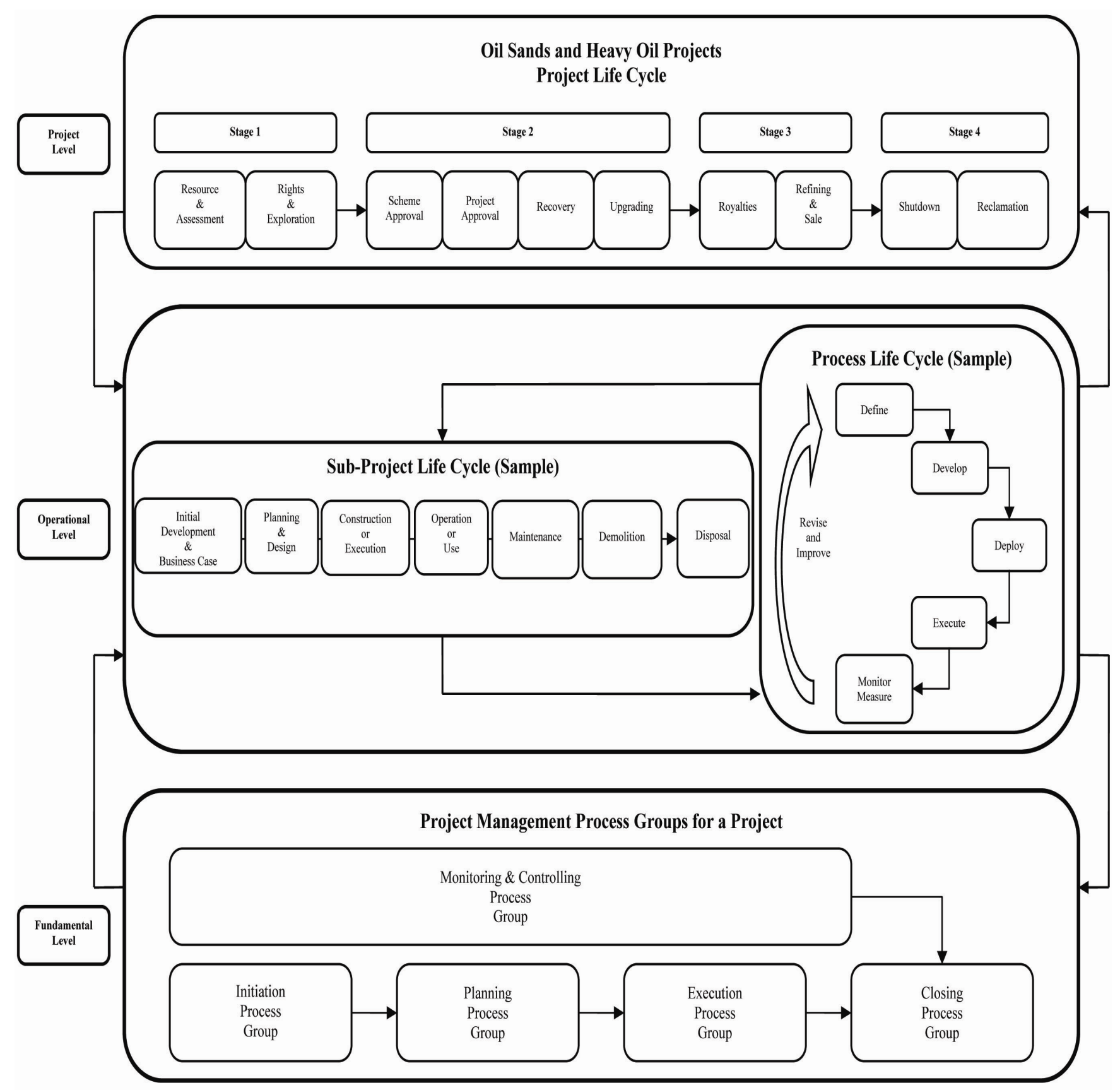

Figure 1. Interaction amongst project, fundamental, and operation levels for the oil sands and heavy oil projects 


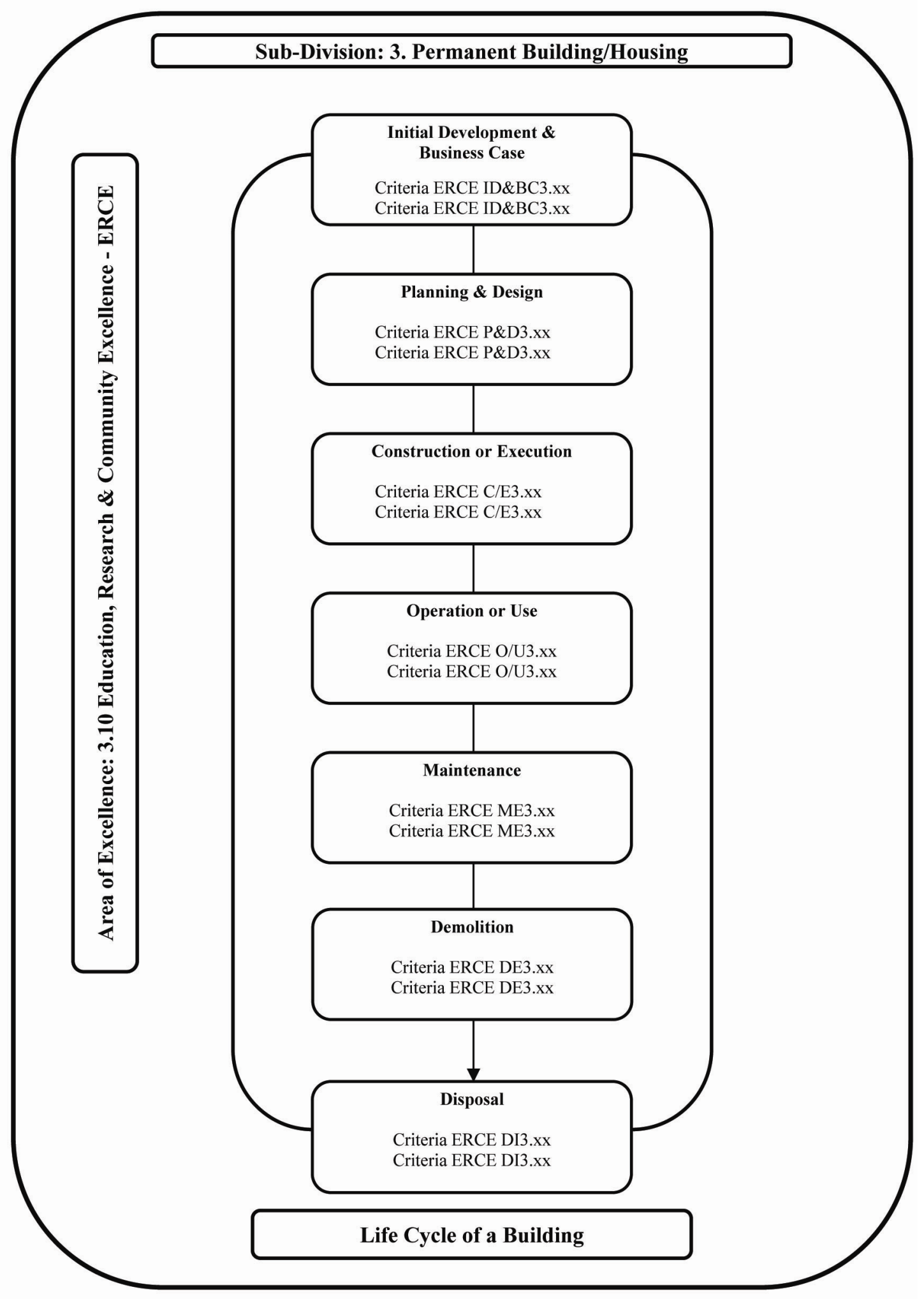

Figure 2. Relationship amongst areas of excellence, subdivision, project life cycle and criteria 